\title{
Effects of Two Phosphonium-Type Ionic Liquids on the Rheological and Thermomechanical Properties of Emulsion Poly(vinyl chloride)- Based Formulations Plasticized with DINP and CITROFOL
}

\author{
Sofia Marceneiro, ${ }^{\dagger}{ }^{\ddagger}$ Qingyun $\mathrm{Hu}^{\dagger}$ Ana M. A. Dias, ${ }^{\dagger}$ Irene Lobo, ${ }^{\ddagger}$ Isabel Dias, ${ }^{\ddagger}$ Elizabete de Pinho, ${ }^{\ddagger}$
} M. Graça Rasteiro, ${ }^{*}{ }^{\dagger}$ and Hermínio C. de Sousa ${ }^{*}{ }^{\dagger}$

${ }^{\dagger}$ CIEPQPF, Chemical Engineering Department, FCTUC, University of Coimbra, Rua Sílvio Lima, Pólo II-Pinhal de Marrocos, 3030-790 Coimbra, Portugal

¥TMG Automotive, Apartado 14, São Cosme do Vale, 4761-912 Vila Nova de Famalicão, Portugal

Supporting Information

\begin{abstract}
Industrial poly(vinyl chloride) (PVC) plastisols are often formulated using phthalate plasticizers due to their costeffectiveness and high compatibility with PVC. However, there is a current need to replace these additives by plasticizers that (i) present reduced migration/leaching and volatilization profiles, (ii) can optimize production processes while maintaining the performance of the final plasticized materials, and (iii) reduce toxicological risks to consumers and to the environment. The main objective of this work was to evaluate the effects of the partial replacement $(15$ and $30 \%(w / w))$ of two conventional plasticizers (diisononyl phthalate (DINP) and acetyltri-2-ethylhexyl citrate (CITROFOL AHII)) by two low-volatility ionic liquids of the phosphonium-type (trihexyl(tetradecyl) phosphonium dicyanamide and trihexyl(tetradecyl) phosphonium bis(trifluoromethylsulfonyl)imide) on the rheological and thermomechanical properties of an emulsion-grade PVC which is usually employed in the production of automotive industry upholsteries. Rheological profiles and plastisols' particle size distributions were monitored over time (up to 14 days) to study the effects of plastisols aging on the thermal stability and thermomechanical properties of PVC films obtained after gelation of the plastisols. Obtained results showed that the incorporation of these two phosphonium-type ionic liquids into DINP- and CITROFOL-based PVC plastisols significantly reduced their viscosities and changed their rheological profiles (from pseudoplastic to near-Newtonian behavior). Plastisols aging had a noticeable impact on the final thermomechanical properties of PVC films plasticized with DINP while no significant effects were observed for films plasticized with CITROFOL. These results are in good agreement with the correspondent timedependent rheological profiles.
\end{abstract}

\section{INTRODUCTION}

Flexible poly(vinyl chloride)-based (PVC-based) materials are used for diverse applications which include packaging, coating, biomedical devices, artificial leather, and automobile upholsteries/finishes (e.g., carpets, seats, headliners, dashboards, and door and instrument panels), among others. These flexible materials are obtained by gelation of plastisols which consist in the dispersion (suspension) of fine particles of emulsion PVC (E-PVC) into liquid plasticizers (typically 50-60\% E-PVC/ $50-40 \%$ plasticizer, wt/wt). Other additives such as thermostabilizers, fillers, and/or pigments can also be added to the formulation depending on the envisaged final application. ${ }^{1-3}$ During this process, which is one of the most commonly employed methods in industry, ${ }^{4}$ PVC particles are first solvated and swollen by the plasticizer and then processed by melting, molding, dipping, or casting, to obtain the final flexible product. ${ }^{1,5,6}$ Plastisol processing conditions are largely dependent on its rheological behavior which in turn depends on the PVC particle size and size distribution (before and after swelling), solids concentration, processing temperature, and plasticizer type/amount. $^{7-12}$

Plasticizers are low/medium molecular weight compounds that reduce the glass transition temperature $\left(T_{\mathrm{g}}\right)$ of a given polymer by breaking interchain dipole interactions and increasing the free volume between the polymer chains. ${ }^{2}$ Different plasticizers may interact differently with E-PVC particles leading to the formation of swollen particles with different sizes, structures, distribution profiles, and agglomeration tendencies. These properties will ultimately impact the rheological and the processing behavior of the plastisols as well as the thermomechanical properties of the processed polymer. ${ }^{3,5-7,13,14}$ Phthalates such as di(2-ethylhexyl) phthalate (DEHP), diisononyl phthalate (DINP), and diisodecyl phthalate (DIDP) are among the most commonly used PVC plasticizers. ${ }^{15,16}$ However, phthalates interact weakly with PVC chains and present relatively high volatility which leads to plasticizer migration and diffusion from the polymer matrix, with consequent decrease of the thermomechanical performance of the polymer, ${ }^{17}$ and general increased concern regarding toxicity and human health risks. ${ }^{18,19}$ As an example, the U.S. Environmental Protection Agency (EPA) for the automotive industry is demanding a significant reduction of the amount of volatile organic compounds (VOCs) emitted from car interior

Received: June 13, 2014

Revised: September 18, 2014

Accepted: September 22, 2014

Published: September 22, 2014 
Table 1. Physicochemical Properties of Plasticizers and Ionic Liquids Used in This Work

\begin{tabular}{|c|c|c|c|c|}
\hline \multirow[b]{2}{*}{ Properties } & \multicolumn{2}{|c|}{ Plasticizers } & \multicolumn{2}{|c|}{ Ionic Liquids } \\
\hline & DINP & CITROFOL ${ }^{\circledR}$ AHII & Ph-DCA & $P h-T f_{2} N$ \\
\hline Synonym & Di-isononyl phthalate & $\begin{array}{l}\text { Acetyltri-2-ethylhexyl } \\
\text { citrate }\end{array}$ & $\begin{array}{l}\text { Trihexyl(tetradecyl)phosphonium } \\
\text { dicyanamide }\end{array}$ & $\begin{array}{l}\text { Trihexyl(tetradecyl)phosphonium } \\
\text { bis(trifluoromethylsulfonyl)imide }\end{array}$ \\
\hline Chemical Formula & $\mathrm{C}_{26} \mathrm{H}_{42} \mathrm{O}_{4}$ & $\mathrm{C}_{32} \mathrm{H}_{58} \mathrm{O}_{8}$ & $\mathrm{C}_{34} \mathrm{H}_{68} \mathrm{~N}_{3} \mathrm{P}$ & $\mathrm{C}_{34} \mathrm{H}_{68} \mathrm{~F}_{6} \mathrm{NO}_{4} \mathrm{PS}_{2}$ \\
\hline \multicolumn{5}{|l|}{ Chemical Structure } \\
\hline $\begin{array}{l}\text { Molecular Weight } \\
\left(\text { g.mol } \mathrm{mol}^{-1}\right)\end{array}$ & 420.6 & 570.8 & 549.9 & 764.0 \\
\hline $\begin{array}{l}\text { Density } \\
\left(\mathrm{g} . \mathrm{cm}^{-3}\right)\end{array}$ & 0.975 & 0.980 & 0.898 & 1.065 \\
\hline $\begin{array}{l}\text { Viscosity } \\
(\mathrm{mPa} . \mathrm{s})\end{array}$ & 78.0 & 130.0 & 280.4 & 292.5 \\
\hline 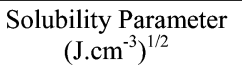 & $15.7^{\mathrm{a}}$ & $15.3^{b}$ & $20.4^{\mathrm{c}}$ & $19.1^{\mathrm{c}}$ \\
\hline
\end{tabular}

${ }^{a}$ According to Gil et al. ${ }^{22}{ }^{b}$ Calculated using van Krevelen's group contribution. ${ }^{37}{ }^{c}$ According to Kilaru and Scovazzo. ${ }^{38}$

components (to avoid fogging) as well as of the amount of plasticizers that migrate and are lixiviated after contact of the plasticized PVC-based materials with skin and topically applied creams, sun light protectors, and so on.

Several alternatives have been proposed to substitute phthalate-based plasticizers as is the case of the phthalateinspired molecules diisononyl cyclohexane-1,2-dicarboxylate (DINCH) and diisononyl cyclohex-4-ene-1,2-dicarboxylate (Neocizer). ${ }^{20}$ These molecules proved to slightly delay the gelation of PVC plastisols and decrease plasticizer migration, thus improving the stability of the processed PVC. Among nonphthalate plasticizers, low molecular weight (e.g., citrates, trimellitates, adipates, azelates, and cyclohexane derivatives, etc.) and polymeric additives (elastomers and polyesters) have also been used to plasticize PVC. ${ }^{18}$ Recently, biobased plasticizers such as tri-2-ethylhexyl citrate (CITROFOL) were considered promising greener alternatives obtained from biodegradable and renewable sources and with low toxicity. ${ }^{21-24}$ Despite the mentioned advantages these alternatives still present some drawbacks such as high viscosity and migration/exudation, low compatibility, and low plasticization efficiency. ${ }^{24,25}$

Ionic liquids (ILs) present a set of interesting properties, in particular their high thermal stability, low flammability, and negligible volatility, ${ }^{26-28}$ that led them to be tested as new effective plasticizers for PVC. Previously reported literature data showed that ammonium-, imidazolium-, and phosphoniumbased ILs are able to successfully decrease the $T_{\mathrm{g}}$ of PVC and improve its thermal stability. ${ }^{29-33}$ Moreover, and although ammonium- and imidazolium-based ILs have presented good plasticizing results, quaternary phosphonium cations (PhILs) have higher thermal and chemical stability. ${ }^{29-35}$ They also have higher molar volumes and tunable hydrophobicity, that can be achieved by combining the hydrophobic phosphonium cation with anions with different hydrophilicities (such as chlorine or bis(trifluoromethanesulfonyl) imide). These properties allow PhILs to (i) increase PVC interchain free volume and improve plasticization; (ii) retard plasticizer migration, since diffusion of larger ions through/from the bulk of the matrix is hampered; and (iii) potentiate plasticizer-PVC miscibility, which reduces the risk of plasticizer migration and improves the homogeneity of the plasticized materials.

PhILs alone have already been successfully used as biocompatible PVC plasticizers, ${ }^{30}$ however, and so far, they were incorporated at maximum amounts of $20 \%$ and $30 \%$ (w/ $\mathrm{w}$ ) before being processed by film casting ${ }^{33}$ and hot-melt extrusion, ${ }^{31}$ respectively. Higher incorporated amounts led to $\mathrm{PhIL}$ exudation most probably due to their relatively high viscosity ${ }^{37}$ that may make difficult their diffusion into PVC particles. This feature may limit the use of PhILs to prepare plastisols and consequently limit their broader industrial application as plasticizers. To overcome this issue, and simultaneously benefit from the advantages of using ILs, partial substitution of conventional plasticizers by ILs should be considered. Therefore, the aim of this work was to study the influence of the partial substitution of diisononyl phthalate (DINP) and acetyltri-2-ethylhexyl citrate (CITROFOL AHII) by PhILs, namely, trihexyl(tetradecyl)phosphonium dicyanamide $\left(\left[\mathrm{P}_{6,6,6,14}\right][\mathrm{dca}]\right)$ and trihexyl(tetradecyl)phosphonium bis(trifluoromethylsulfonyl)imide $\left(\left[\mathrm{P}_{6,6,6,14}\right]\left[\mathrm{Tf}_{2} \mathrm{~N}\right]\right)$, on the rheological behavior and on the particle size distributions of E-PVC-based plastisols, as well as on the thermomechanical properties of the films obtained after gelation of those plastisols. The selection of these PhILs in particular, over the large number of available possibilities, is justified by their already demonstrated higher thermal stability, low tendency to lixiviate into water and saline solutions (below $1.5 \%$ in buffer and $2 \%$ in water for both PhILs), and very low toxicity against human cells. $^{30}$ Plastisol aging effects were also accounted for by studying those properties for fresh and aged (stored up to 14 days) plastisols. This information is crucial for companies that process PVC-based materials and which are facing tight legislation that demands the substitution of traditionally used plasticizers by new nontoxic and nonvolatile alternatives (e.g., 
CITROFOL and PhILs) and that simultaneously need to guarantee efficient processability and high performance of the final plasticized materials.

\section{EXPERIMENTAL SECTION}

2.1. Materials. DINP and E-PVC powder (VICIR E 1970P) were supplied by TMG Automotive, Vila Nova de Famalicão, Portugal.CITROFOL AHII (hereafter abbreviated as CITROFOL) was supplied by Jungbunzlauer Inc., Basel, Switzerland. The employed PhILs, $\left[\mathrm{P}_{6,6,6,14}\right][\mathrm{dca}]$ and $\left[\mathrm{P}_{6,6,6,14}\right]$ $\left[\mathrm{Tf}_{2} \mathrm{~N}\right]$ (commercially available as Cyphos 105 and Cyphos 109, respectively), were obtained from Cytec Industries, Niagra Falls, Ontario, Canada, with purities $>98 \%$. The chemical structures and some physical-chemical properties of the plasticizers and of the PhILs used in this work are shown in Table 1 . $n$-Heptane (purity > 99\%) and acetone (purity > 99\%) were obtained from José M. Vaz Pereira SA, Sintra, Portugal and Sigma-Aldrich, Sintra, Portugal, respectively. All chemicals were used as received and without further purification.

2.2. Preparation of E-PVC Plastisols and Corresponding Flexible Films. Plastisols samples were prepared at room temperature by mechanical stirring (Janke \& Kunkel GmbH \& Co. HG, IKA-Werk, RW 24 basic, Staufen, Germany) of all components ( 150 parts of plasticizer per 100 parts of polymer) at $25 \mathrm{rpm}$ for $2.5 \mathrm{~h}$. The total plasticizer amount considers the use of conventional plasticizer alone or its mixture with PhILs $(15 \%$ and $30 \%(\mathrm{w} / \mathrm{w}))$. The compositions of the prepared plastisols are given in Table $\mathrm{S} 1$ as Supporting Information.

After stirring, the homogeneous mixture was vacuumed for 1 $h$ at 1 mbar to eliminate entrapped air. The aging of the plastisols consisted of the storage of the samples in silica gel at ambient conditions (temperature $\sim 20{ }^{\circ} \mathrm{C}$ ) up to 14 days. Aging was monitored by rheological and particle size distribution measurements at different time intervals between "0" and " 14 " days $(0,0.2,1,2,7$, and 14 days) after plastisol preparation. Each sample was coded as conventional plasticizer/PhIL/weight percentage of conventional plasticizer that was substituted by PhIL. $\left[\mathrm{P}_{6,6,6,6,14}\right][\mathrm{dca}]$ and $\left[\mathrm{P}_{6,6,6,14}\right]\left[\mathrm{Tf}_{2} \mathrm{~N}\right]$ were identified as $\mathrm{Ph}-\mathrm{DCA}$ and $\mathrm{Ph}-\mathrm{Tf}_{2} \mathrm{~N}$, respectively. For instance DINP/Ph-DCA/15 refers to an E-PVC formulation plasticized with 85 wt \% DINP and 15 wt \% Ph-DCA over the total plasticizer amount used (60 wt \%).

Flexible E-PVC films with a thickness of $1 \mathrm{~mm}$ were obtained for each formulation, at $t=0$ and $t=14$ days, by spreading the plastisol over a preheated special support paper (VERSAKOTE release paper) and heating in a ventilated oven at $210^{\circ} \mathrm{C}$ for 1 min.

2.3. Characterization Methodologies. 2.3.1. PVC Powder Properties. The molecular weight $\left(\mathrm{Mn}^{\mathrm{GPC}}\right)$ and polydispersity (PDI) of PVC VICIR 1970P were measured using high-performance gel permeation chromatography (HPSEC). The column set consisted of a PL $10 \mu \mathrm{m}$ guard column $(50 \mathrm{~mm}$ $\times 7.5 \mathrm{~mm})$ followed by one Viscotek T200 column $(6 \mu \mathrm{m})$, one MIXED-E PL gel column $(3 \mu \mathrm{m})$, and one MIXED-C PL gel column $(5 \mu \mathrm{m})$. A high-performance liquid chromatography (HPLC) dual piston pump (Kanuer K-1001) was set with a flow rate of $1 \mathrm{~mL} / \mathrm{min}$. The eluent (tetrahydrofuran) was previously filtered through a $0.2 \mu \mathrm{m}$ filter. The system is also equipped with a Kanuer online degasser. Measurements were performed at $30{ }^{\circ} \mathrm{C}$ using an Elder $\mathrm{CH}-150$ heater. Before injection $(100 \mu \mathrm{L})$, the sample was filtered through a poly(tetrafluoroethylene) (PTFE) membrane with $0.2 \mu \mathrm{m}$ pore. The system was calibrated with polystyrene (PS) standards. $\mathrm{Mn}^{\mathrm{GPC}}$ and PDI were obtained by Universal Calibration (the viscosity was measured directly by the viscometer detector) using the OmniSEC software version 4.6.1.354.

The density $\left(\mathrm{g} / \mathrm{cm}^{3}\right)$ of the E-PVC solid particles was measured by helium pycnometry (Accupyc 1330 Micromeritics, Micromeritics Instrument, Norcross, GA, USA). The average surface charge of solid particles (dispersed at $1 \%(w / w)$ in Milli-Q water) was measured by electrophoretic light scattering using a Zetasizer Nano ZS (Malvern Instruments, Malvern, U.K.). Results are presented as an average of at least three measurements. The particle size distribution of PVC powder was measured by laser diffraction spectroscopy (LDS; Mastersizer 2000, Malvern).

2.3.2. Plastisol Gelation. Plastisol gelation was analyzed using the acetone immersion test following the ASTM D2152 standard. ${ }^{36}$ Samples of E-PVC gelled films $(2 \mathrm{~cm} \times 3 \mathrm{~cm})$ were completely immersed in acetone for $45 \mathrm{~min}$. If the samples disintegrate after this period, it can be concluded that the plasticized PVC matrix was not effectively gelled.

2.3.3. Rheological Measurements. Rheological properties were measured using a controlled stress rheometer (Model RS1, Haake, Vreden, Germany) with a cylindrical sensor system Z34 DIN connected to a thermocontroller recirculation bath (Haake Phoenix II). Temperature was set constant at $\pm 23{ }^{\circ} \mathrm{C}$. Flow tests were performed for different aging times $(0,0.2,1,2$, 7 , and 14 days). The rheometer worked in controlled stress mode, and the shear rate was varied between 0.5 and $30 \mathrm{~s}^{-1}$ using $50 \mathrm{~mL}$ of plastisol in each test. Results are presented as the average of at least three measurements for each sample.

2.3.4. Particle Size Distribution of the E-PVC Particles in Plastisols. The particle size distributions of the E-PVC plastisols were measured by LDS using a Mastersizer 2000 (Malvern). Plastisol samples were dispersed at $1 \%(\mathrm{w} / \mathrm{v})$ in $n$ heptane following a previously reported procedure. ${ }^{6}$ Particle size measurements were carried out without and with ultrasound (displacement $(5 \mathrm{kHz}) /$ time $(15 \mathrm{~s}))$. LDS results are presented as the average of at least three measurements for each sample. Measurements were performed for plastisols formulated only with DINP or CITROFOL and with 15 wt \% of each PhIL (at higher PhIL amount the formulations do not disperse in $n$-heptane).

2.3.5. Thermomechanical Stability. The thermal stability of film samples obtained from fresh plastisols $(t=0$ days $)$ and after aging for 14 days was analyzed by mass loss measurements (TGA) using a thermogravimetric analyzer (TA Instruments, Q500, Newcastle, DE, USA). Experiments were carried out from room temperature to $600{ }^{\circ} \mathrm{C}$, at $10^{\circ} \mathrm{C} / \mathrm{min}$ under dry nitrogen atmosphere $(40 \mathrm{~mL} / \mathrm{min})$. Dynamic mechanical thermal analysis (DMTA) was employed to evaluate the effect of the plasticizer mixtures and plastisol aging on the mechanical properties of the processed films. Measurements were performed using the constrained layer damping mode at 1, 5, and $10 \mathrm{~Hz}$ and with a displacement of $0.05 \mathrm{~mm}$ using Triton equipment (Tritec 2000, Watford, U.K.). The temperature profile was obtained at $2{ }^{\circ} \mathrm{C} / \mathrm{min}$ (from -150 to $110^{\circ} \mathrm{C}$ ) with a time delay of $1 \mathrm{~s}$. Measurements were performed for films plasticized only with DINP or CITROFOL and for films formulated with 15 wt \% of each PhIL.

\section{RESULTS AND DISCUSSION}

3.1. Characterization of the E-PVC Particles. The EPVC particles have a median diameter of $\sim 20 \mu \mathrm{m}\left(d_{50}\right)$, which 
is a typical value for emulsion $\mathrm{PVC},{ }^{6,9-11}$ and negative surface charge ( $\zeta$ potential $\sim-44 \mathrm{mV}$ ). Results obtained from the particle size distribution profile also show that the particles present relatively high uniformity $\left(d_{90} / d_{10}=8.1\right)$ and narrow particle size distribution (low $\left(d_{90}-d_{10}\right) / d_{50}$ ratio). More detailed information is given in Table S2 of the Supporting Information.

3.2. Plastisol Aging. 3.2.1. Effect of Aging on the Rheology of Plastisols Formulated with and without PhILs. The rheological behavior of plastisols formulated only with DINP or CITROFOL is compared in Figure 1 at different time
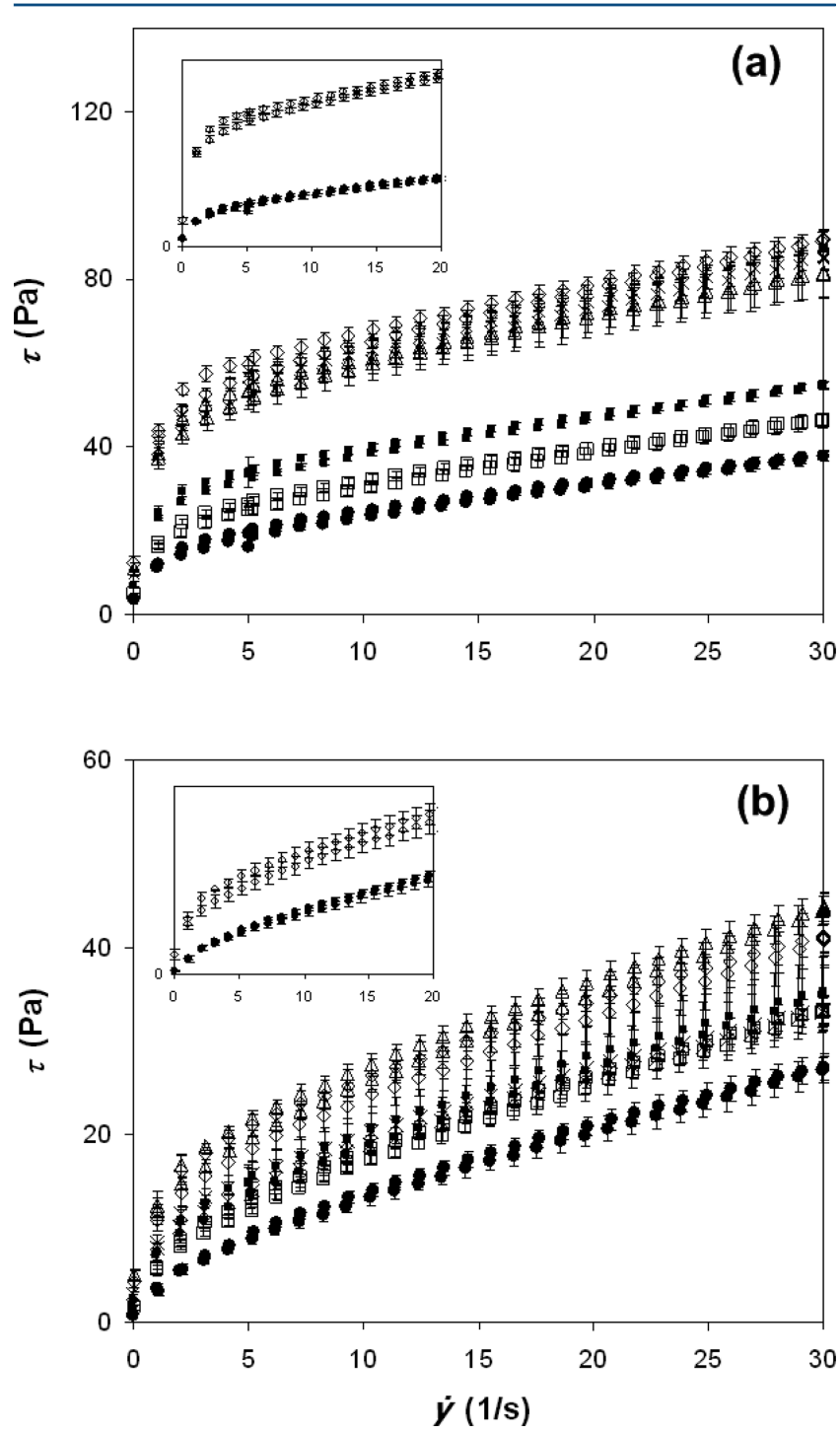

Figure 1. Flow tests of DINP- (a) and CITROFOL-based (b) plastisols at different time points: 0 days (fresh plastisol; $\bullet$ ), 0.2 days $(\square), 1$ day $(\square), 2$ days $(*), 7$ days $(\Delta)$, and 14 days $(\diamond)$. The inset represents data only for fresh and 14 days aged plastisols in order to better visualize the higher hysteresis observed for CITROFOL-based plastisols after aging.

points. Results show that, for the same shear strain interval (0$30 \mathrm{~s}^{-1}$ ), aging is more pronounced for samples formulated with DINP (shear stress ranges between 38 and $90 \mathrm{~Pa}$ ) when compared to CITROFOL (shear stress ranges between 28 and $45 \mathrm{~Pa}$ ). This effect is more evident after storage of the plastisol for 7 days where slightly higher hysteresis (typical for pastes) also occurs, confirming the thixotropic behavior of the DINPbased formulation. Both plastisols behave as pseudoplastic (or shear thinning) fluids, and this behavior is more pronounced after aging, mainly for DINP-based plastisols. Moreover, both plastisols present an initial yield stress that indicates the presence of intermolecular particle-particle and particleplasticizer interactions (van der Waals forces, dipole-dipole interactions, hydrogen bonds, and electrostatic interactions). This means that these plastisols will only flow when the applied external stress overcomes those intermolecular forces, which in this study are higher for the PVC-DINP system (higher initial yield stress). This result indicates that stronger interactions are established between PVC and DINP which justifies its wider use as PVC plasticizer. An efficient plasticizer must interact strongly with the polymer. As a general rule, structural similarity (similar solubility parameters) favors solubility/ miscibility. According to the definition of the Gibbs free energy of solution a compound will be a good solvent for a particular polymer when $\Delta G$, calculated from eq 1 , is negative: ${ }^{22}$

$$
\Delta G=\Delta H-T \Delta S
$$

where $\Delta H$ is the enthalpy of mixing (J), $\Delta S$ is the entropy of mixing $(\mathrm{J} / \mathrm{K})$, and $T$ is the absolute temperature $(\mathrm{K})$. For an amorphous polymer the entropy of solution is small but positive. Therefore, the sign of $\Delta G$ depends on the magnitude of $\Delta H$ which can be calculated from the Hildebrand equation:

$$
\Delta H=\phi_{\mathrm{s}} \phi_{\mathrm{p}}\left(\delta_{\mathrm{s}}-\delta_{\mathrm{p}}\right)^{2}
$$

where $\phi_{\mathrm{s}}$ and $\phi_{\mathrm{p}}$ are the volume fractions of the solvent and polymer, respectively, and $\delta_{\mathrm{s}}$ and $\delta_{\mathrm{p}}$ are their respective solubility parameters. The enthalpies of mixing calculated for plastisols formulated with CITROFOL are almost twice those calculated for DINP, which confirms favorable PVC-DINP interactions (Table S1, Supporting Information).

The influence of PhILs on the flow curves of the plastisols is shown in Figure 2. In both cases there is a clear change in the flow curve profiles which present a Newtonian-like behavior after $\mathrm{PhIL}$ incorporation, this effect being more pronounced when using Ph-DCA as plasticizer substitute. In the case of plastisols formulated with DINP, both PhILs decrease shear stress by almost $55 \%(\mathrm{Ph}-\mathrm{DCA})$ and $30 \%\left(\mathrm{Ph}-\mathrm{Tf}_{2} \mathrm{~N}\right)$ with no significant influence of the PhIL substituted amount. In the case of plastisols formulated with CITROFOL, only Ph-DCA led to a decrease in the shear stress by almost 50\% (effect similar to that described for formulations with DINP) and also with no significant dependence on the PhIL substituted amount. On the contrary, partial substitution of CITROFOL by $\mathrm{Ph}-\mathrm{Tf}_{2} \mathrm{~N}$ does not alter (at $15 \%(\mathrm{w} / \mathrm{w})$ substitution) or only slight increases ( $\sim 20 \%$ at $30 \%(\mathrm{w} / \mathrm{w})$ substitution) the plastisol shear stress.

Aging of DINP- and CITROFOL-based plastisols was also analyzed, and the results are presented in Figure 3 in terms of changes in the limit viscosity (viscosity at the highest shear rate) of the plastisols. As expected, viscosity follows the tendency previously observed for the flow profiles: DINP-based plastisols are significantly more sensitive to aging and present higher viscosity than CITROFOL-based ones. This is an interesting result considering the higher viscosity of pure CITROFOL when compared to DINP (Table 1) and also the fact that a lower amount of CITROFOL is incorporated in those formulations (in molar terms, based on the molecular weight of the plasticizers given in Table S1, Supporting Information). An increase in the plastisols viscosity with time is a known and previously reported behavior ${ }^{1,6,8-14}$ and indicates 

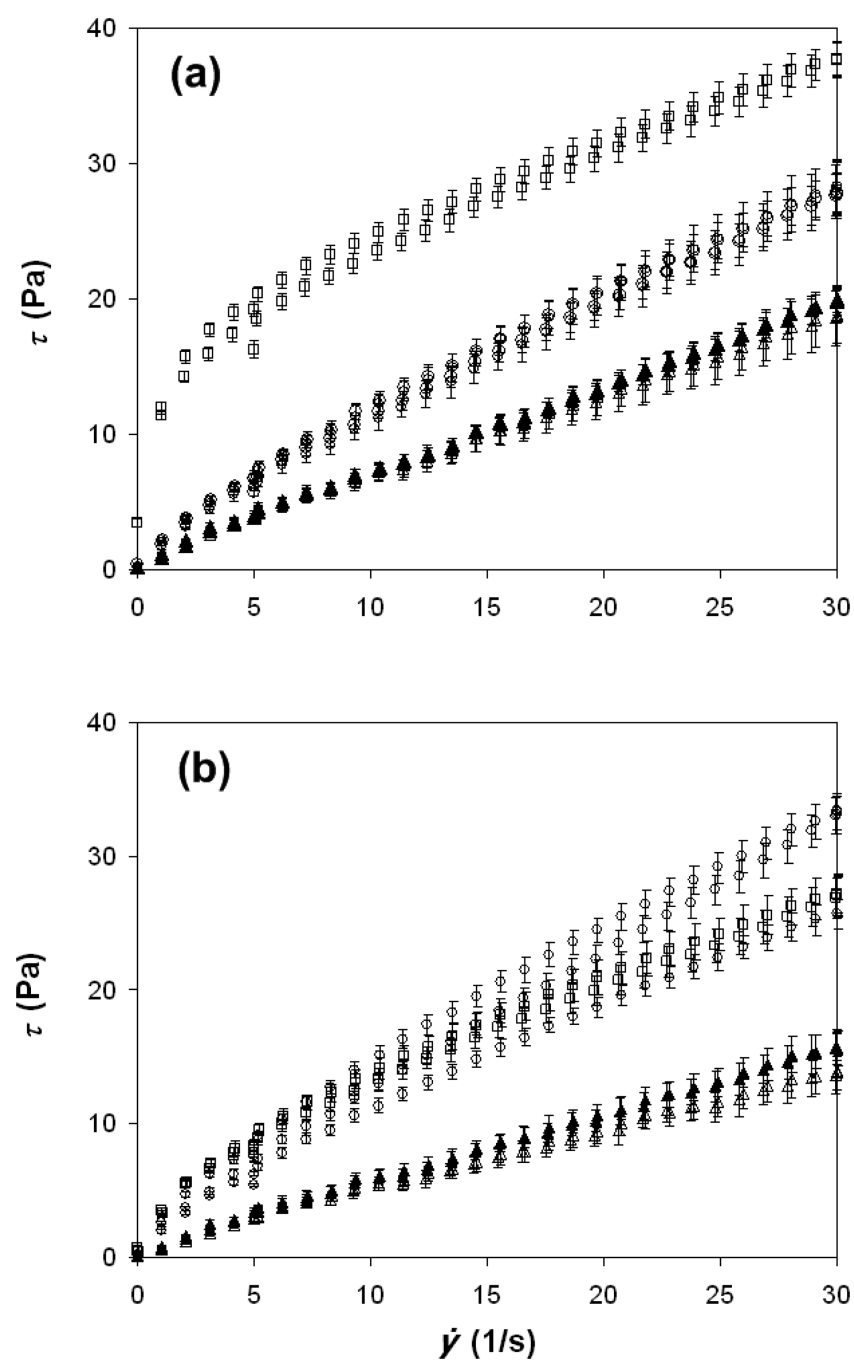

Figure 2. Flow tests of DINP (a) and CITROFOL (b) fresh plastisols formulated without ionic liquid $(\square)$ and with different amounts of each of the studied ionic liquids, namely: $15 \%(\mathrm{w} / \mathrm{w}) \operatorname{Ph}-\mathrm{DCA}(\Delta)$, $30 \%(\mathrm{w} / \mathrm{w}) \mathrm{Ph}-\mathrm{DCA}(\boldsymbol{\Delta}), 15 \%(\mathrm{w} / \mathrm{w}) \mathrm{Ph}-\mathrm{Tf}_{2} \mathrm{~N}(\mathrm{O})$, and $30 \%(\mathrm{w} / \mathrm{w})$ $\mathrm{Ph}-\mathrm{Tf}_{2} \mathrm{~N}(\mathbf{O})$.

that the plasticizer starts to break particles' agglomerates and to swell those particles. Therefore, the higher viscosity changes observed after aging for the DINP-based formulations also confirm the higher DINP-PVC affinity.

The presence of PhILs significantly decreases the viscosity of both plastisols, except when $\mathrm{Ph}-\mathrm{Tf}_{2} \mathrm{~N}$ is used to partially substitute CITROFOL. Plastisols formulated with $\mathrm{Ph}-\mathrm{Tf}_{2} \mathrm{~N}$ always present higher viscosities (at 15 and $30 \%(\mathrm{w} / \mathrm{w}$ ) substitution) when compared with Ph-DCA despite it being incorporated at a lower amount (in molar terms). Aging effects are more pronounced when using $\mathrm{Ph}-\mathrm{Tf}_{2} \mathrm{~N}$ for both DINP- and CITROFOL-based plastisols probably due to the higher molecular weight of this PhIL (Table 1) that may make difficult its diffusion and incorporation into the E-PVC particles.

Overall, the rheological behavior of the studied plastisols seems to indicate that PhIL incorporation into the formulations simultaneously decreases the flow resistance and the viscosity of the plastisols which may represent a significant advantage for plastisol processing. These results are also in agreement with the calculated mixing enthalpies for the PVC-plasticizer-PhIL formulations (Table S1, Supporting Information). Results show that both PhILs enhance the compatibility of the PVC(plasticizer + PhIL) mixtures with a consequent decrease in their mixing enthalpies when compared to formulations prepared without IL. This means that the presence of PhILs affects (favorably) the type and intensity of PVC-plasticizer interactions. Moreover that influence seems to be dependent on the type/strength of the DCA/Tf ${ }_{2} \mathrm{~N}-\mathrm{PVC}$ or even DCA/ $\mathrm{Tf}_{2} \mathrm{~N}$-plasticizer interactions since lower mixing enthalpies were calculated for formulations prepared with Ph-DCA when compared to $\mathrm{Ph}-\mathrm{Tf}_{2} \mathrm{~N}$.

It is important to note that the mixing enthalpies of the PVC-plasticizer-PhIL system were calculated by using PhILs' solubility parameters obtained from viscosity data for the pure PhILs. ${ }^{38}$ This is a commonly used method to calculate solubility parameters of low-volatility compounds (as in the case of PhILs), for which it is difficult or even impossible to obtain those parameters from enthalpy of vaporization data. The advantage of this method is that it permits one to express the cation-anion and ion-pair interactions of the pure IL instead of IL-solvent interactions given by other approaches. ${ }^{39}$ However, it only considers polar interactions, such as dipoledipole, hydrogen-bonding, and Coulombic interactions, which are the ones that dominate viscosity related interactions. Therefore, these solubility parameters do not take into account the dispersion forces that dominate the nonpolar solubility parameters estimated from infinite dilution activity coefficients or enthalpy of vaporization data. This means that although the solubility parameters used in this work are not able to completely describe PhILs' amphiphilic character (which is responsible for their unique dissolution capacities), they permit one to infer about $\mathrm{Ph}-\mathrm{DCA}$ or $\mathrm{Ph}-\mathrm{Tf}_{2} \mathrm{~N}$ interactions with $\mathrm{PVC}$ if it is assumed that those are mainly governed by polar interactions.

With this restriction in mind it is nevertheless interesting to point out that the slightly higher solubility parameter obtained for Ph-DCA can be associated with a higher hydrogen bond accepting ability of the anion (the $\beta$ Kamlet-Taft parameter) and consequently to stronger Ph-DCA/PVC interactions. Although this relation was previously established for imidazolium-based ILs, ${ }^{39}$ it may be expected to also occur for the PhILs studied in the present work since the $\beta$ Kamlet-Taft parameter has been shown to be dominated by the nature of the anion. ${ }^{40}$ This hypothesis, which needs further confirmation, may help to justify the lower viscosity and larger particle sizes (see later discussion) observed for the formulations prepared with Ph-DCA and may also help in the selection of IL-based plasticizers among the large number of possibilities. It is also important to guarantee that the cohesion forces of the plasticizers must be of the same type as the cohesion forces between polymer chains. If the liquid and the polymer have the same order of cohesion energy, then the liquid will remain stable between the polymer chains and neither the polymer nor the liquid molecules will tend to self-association. ${ }^{41}$ This can be achieved if the plasticizer presents the right polar/nonpolar ratio. In this work the nonpolar contribution is given by the phosphonium cation and the polar contribution by the dicyanamide or bis(trifluoromethylsulfonyl)imide anions. The long alkyl chains of the cation shield the polymer dipoles hampering polymer-polymer interactions while the polar anions interact with the nonpolar segments of the PVC chains which help to "anchor" the plasticizer inside the polymer structure. 


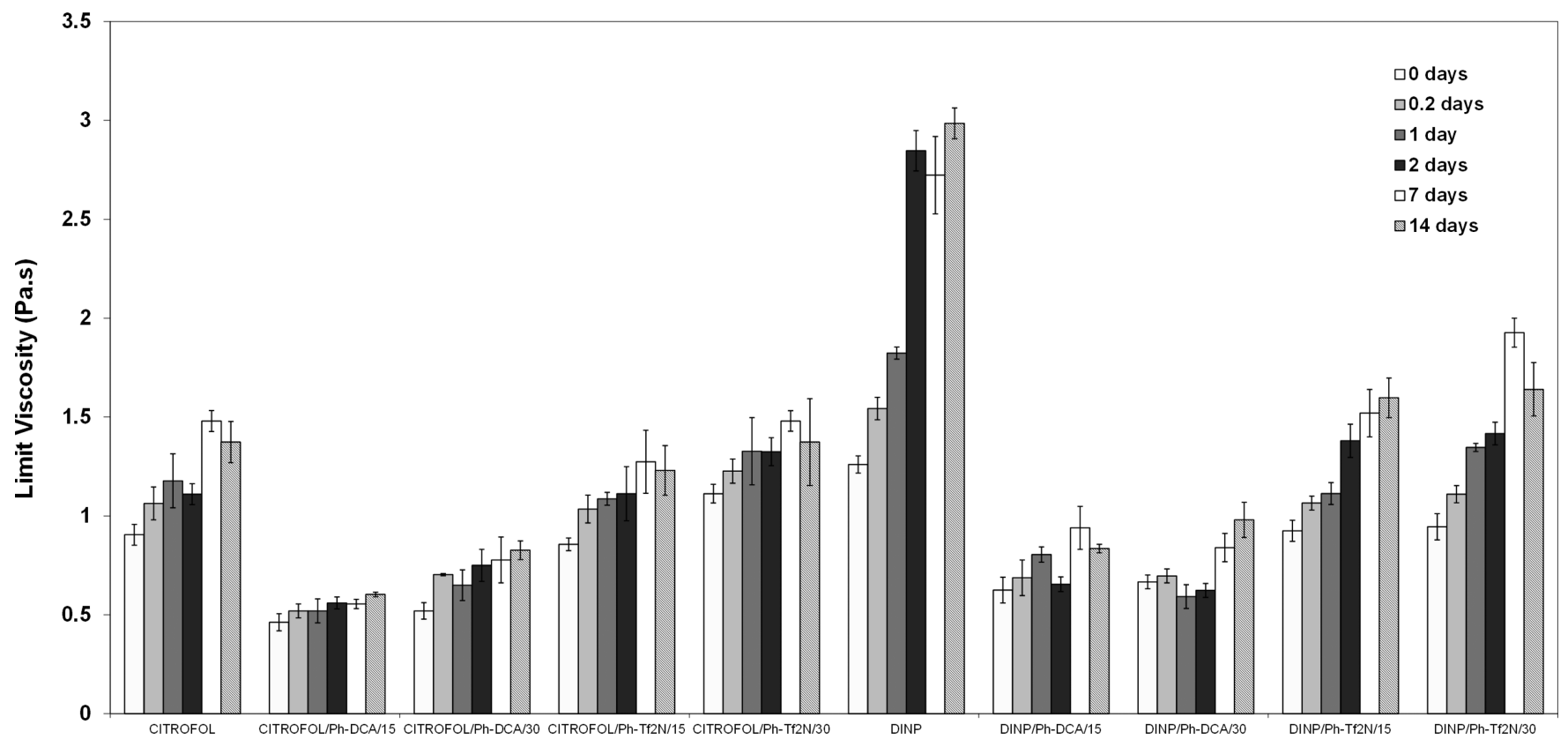

Figure 3. Limit viscosity obtained from the flow tests measured for the plastisols at different aging periods.

3.2.2. Effect of Aging on the Particle Size Distribution of Plastisols Formulated with and without ILs. The PSD distribution of the prepared plastisols was measured at different aging times up to 14 days after preparation (results are summarized in Table S3, Supporting Information). $d_{50}$ of the plastisols formulated with CITROFOL and DINP was found to decrease when compared with $d_{50}$ values measured for the EPVC powder (Table S2, Supporting Information). This behavior is observed immediately after mixing (for fresh plastisols) and indicates that both plasticizers are able to destroy the aggregated PVC particles and increase the overall surface area of the polymer, which is an essential condition to enhance solvency. ${ }^{9}$ However, each plastisol presents a distinct aging behavior, as concluded by comparison of changes in $d_{50}$ values measured for fresh and aged DINP- and CITROFOLbased plastisols which increased by $\sim 235 \%$ and 59\%, respectively. CITROFOL-based plastisols present a constant and more tenuous increase over the entire monitoring period. These results are in agreement with the rheological behavior of the plastisols discussed before and indicate that the higher DINP-PVC affinity enhances solvency and swelling of the EPVC particles, with a consequent increase in $d_{50}$ and in the viscosity of the DINP-based plastisol. The same tendencies were observed from the profiles of the $d_{90} / d_{10}$ and relative width of the distribution $\left.\left(d_{90}-d_{10}\right) / d_{50}\right)$ ratios over the monitoring period which increase as result of a broader PSD. This increase is due to different mechanisms that occur simultaneously, but at different rates, such as particle deagglomeration, particle swelling, solvation, dissolution, and formation of clusters from the swollen particles. ${ }^{15}$ These mechanisms affect the morphology of the aggregates over time and consequently their viscoelastic behavior. The profiles increased gradually up to 7 days with a faster increase up to 14 days (especially for DINP-based plastisols) which probably indicates that after this period swelling dominates over solvation.

The results obtained for the PSD after the incorporation of PhILs into DINP- and CITROFOL-based plastisols show that each PhIL affects the morphology of the aggregates differently and that Ph-DCA is the one that induces the most significant changes (Table S3, Supporting Information). The partial substitution of DINP and CITROFOL by Ph-DCA originates larger aggregates and with a less evident time-dependent behavior. These aggregates are significantly larger for CITROFOL-based formulations, especially for the fresh CITROFOL/Ph-DCA/15 plastisol $\left(d_{50}>1377 \mu \mathrm{m}\right)$, with the formation of PVC-plasticizer clusters. This result may indicate that Ph-DCA promotes aggregation of the partially swollen PVC particles, probably due to stronger DCA-PVC interactions as suggested previously. The presence of clusters may also justify the lowest time-dependent rheological aging profiles of the Ph-DCA substituted plastisols (mainly for CITROFOL/Ph-DCA formulations).

Finally, the stability of the clusters formed from the swollen particles was evaluated through analysis of their PSD with and without the use of ultrasound before data acquisition. In general terms, the effect of ultrasounds is more pronounced for DINPbased plastisols and after 14 days of aging, when the aggregates are larger (Table S3, Supporting Information). These results reflect the more pronounced aging observed for these formulations (Figures 1 and 4) and indicate the formation of highly swollen E-PVC particles clusters that are destroyed by ultrasound. This effect is less noticeable for CITROFOL-based plastisols indicating the formation of stable clusters when the plasticizer is substituted by $\mathrm{Ph}-\mathrm{Tf}_{2} \mathrm{~N}$.

3.3. Thermomechanical Stability of the Films Obtained from the Different Plastisols. The acetone immersion test was used to indirectly access the efficiency of the plasticizer (or plasticizer + PhIL mixtures) to solvate and swell E-PVC particles. ${ }^{2,4}$ Efficient solvation originates cohesive and homogeneous materials after gelation and fusion that do not dissolve when in contact with acetone. The visual aspect of the films obtained after the immersion test show that DINPand CITROFOL-based plastisols with and without PhIL (incorporated at $15 \%(\mathrm{w} / \mathrm{w})$ ) present good gelation (Supporting Information, Figure S1). However, at higher plasticizer substitution, films were fragile probably due to phase segregation with consequent migration/leaching of plasticizer 

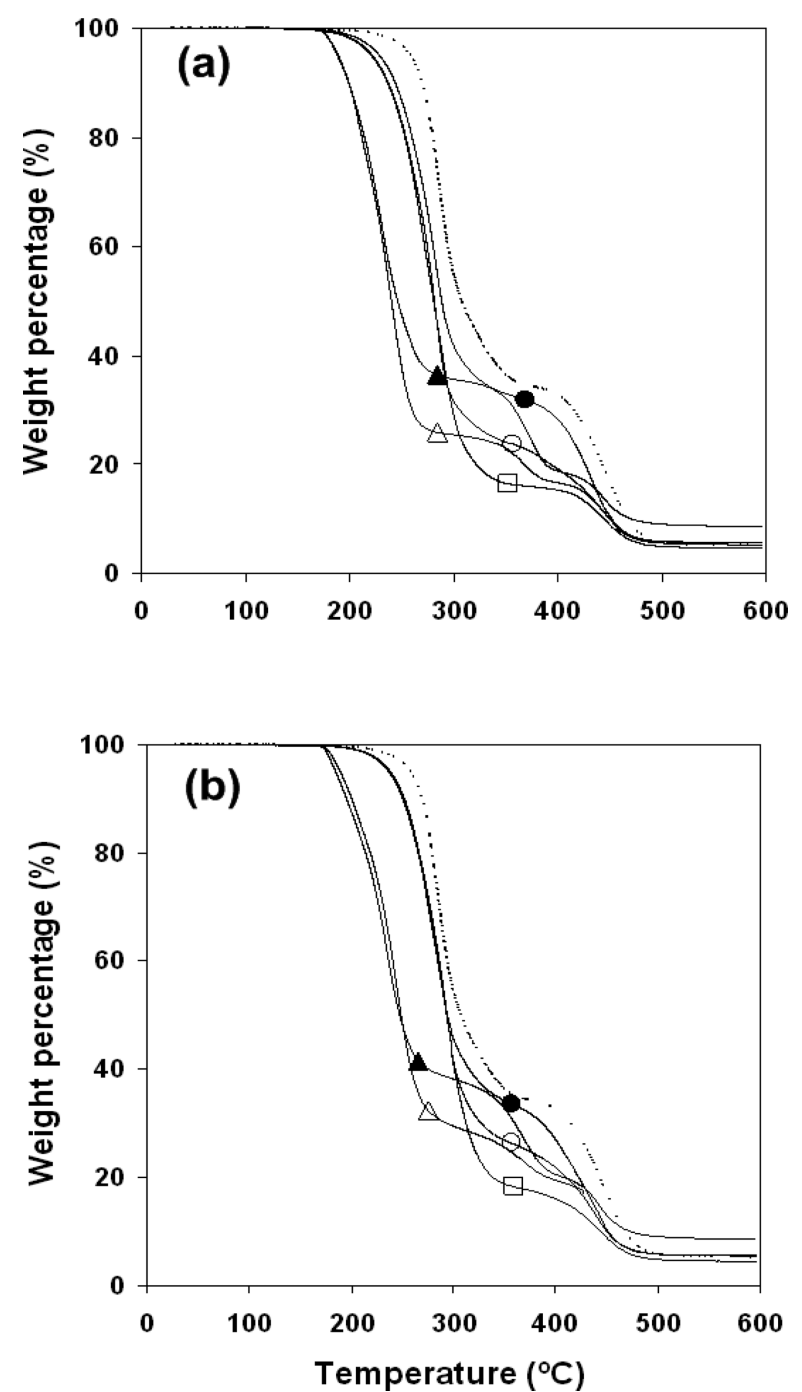

Figure 4. Thermograms of films obtained from fresh plastisols formulated with DINP (a) and CITROFOL (b) without ionic liquid $(\square)$ and with different amounts of each of the studied ionic liquids, namely: $15 \%(\mathrm{w} / \mathrm{w})$ Ph-DCA $(\Delta), 30 \%(\mathrm{w} / \mathrm{w})$ Ph-DCA $(\boldsymbol{\Delta}), 15 \%$ $(\mathrm{w} / \mathrm{w}) \mathrm{Ph}^{-\mathrm{Tf}_{2} \mathrm{~N}}(\mathrm{O})$, and $30 \%(\mathrm{w} / \mathrm{w}) \mathrm{Ph}-\mathrm{Tf}_{2} \mathrm{~N}(\bullet)$. The thermogram measured for the nonprocessed E-PVC powder is also represented for comparison (dashed line).

and/or PhIL from the film. Therefore, thermomechanical analyses of the films were performed only for films formulated without PhIL or with Phil incorporated at $15 \%(\mathrm{w} / \mathrm{w})$.

Thermogravimetric analysis was used to evaluate the thermal stability of the prepared samples at $210{ }^{\circ} \mathrm{C}$ which is the temperature used for plastisol gelation and fusion. One of the main advantages of using PhILs to substitute conventional plasticizers (at least partially) is due to their high thermal stability, which avoids degradation and/or volatilization during processing and ensures long-term stability while in usage. The thermal stability of Ph-DCA, Ph- $\mathrm{Tf}_{2} \mathrm{~N}$, and DINP was previously reported to be equal to $399.3,401.6$, and 304.3 ${ }^{\circ} \mathrm{C}$, respectively (in terms of their peak temperatures $\left(T_{\text {peak }}\right)$ obtained from the first derivative (DTG) of the weight loss vs temperature profiles measured by TGA). ${ }^{30}$ In this work, the $T_{\text {peak }}$ measured for pure CITROFOL was $294.8{ }^{\circ} \mathrm{C}$ which confirms that both PhILs present higher thermal stability than the tested conventional plasticizers.
The temperature-dependent weight loss profiles measured for selected films obtained from fresh plastisols are shown in Figure 4 and compared with that of neat E-PVC. The thermal stability of all the plasticized samples (with and without ILs) was lower than that of nonplasticized E-PVC, as reflected by the decrease in the films' thermal stability at $210{ }^{\circ} \mathrm{C}$ and at $T_{\text {peak }}$ (Table 2). This is a common behavior that is compensated for by the use of thermal stabilizers, which were not used in this work to better access the effect of the plasticizers and of the PhILs on the properties of E-PVC. The weight loss profiles of films plasticized only with DINP or CITROFOL present typical two weight-loss steps usually reported for PVC and which correspond to dehydrochlorination with the formation of polyene (between 200 and $300{ }^{\circ} \mathrm{C}$ ) and chain $\mathrm{C}-\mathrm{C}$ scission (between 350 and $450{ }^{\circ} \mathrm{C}$ ), respectively. ${ }^{42}$ The $T_{\text {peak }}$ of the first step occurs around 270 and $293{ }^{\circ} \mathrm{C}$ for DINP- and CITROFOL-based films, respectively, while the $T_{\text {peak }}$ of the second step occurs around $450{ }^{\circ} \mathrm{C}$ in both cases. Moreover the weight loss of the films at $210{ }^{\circ} \mathrm{C}$ is lower when CITROFOL is used as plasticizer. These results indicate that E-PVC films plasticized with CITROFOL present higher thermal stability than those plasticized with DINP. The effect of PhILs on the thermal stability of the films is clearly dependent on the PhIL type or, more particularly, on the PhIL anion type since both PhILs have the same cation. As can be also seen in Figure 4 and Table 2, the incorporation of Ph-DCA significantly decreases the $T_{\text {peak }}$ of both DINP (decreases $25^{\circ} \mathrm{C}$ ) and CITROFOLbased films (decreases $28{ }^{\circ} \mathrm{C}$ ) as well as the films' thermal stability at $210{ }^{\circ} \mathrm{C}$ with weight losses that range from $15 \%$ (CITROFOL/Ph-DCA/15) to $18 \%$ (DINP/Ph-DCA/15). Moreover, and for this PhIL, an intermediate degradation step appears around $380{ }^{\circ} \mathrm{C}$. These results seem to indicate that heating may destabilize the plasticizer/Ph-DCA mixture and/or promote deswelling of the mixture from the E-PVC particles, leaving them exposed to thermal degradation. Moreover, the higher electronegativity of the dicyanamide anion (Ph-DCA), when compared to $\mathrm{Ph}-\mathrm{Tf}_{2} \mathrm{~N}$, may induce dehydrochlorination through a mechanism similar to that previously reported for chloride imidazolium based ILs. ${ }^{43}$ On the contrary, and as shown in Table 2, the incorporation of $\mathrm{Ph}-\mathrm{Tf}_{2} \mathrm{~N}$ generally maintains or slightly increases (in the case of DINP/Ph- $\mathrm{Tf}_{2} \mathrm{~N}$ / 30 ) the thermal stability of the processed films (considering changes in both $T_{\text {peak }}$ and weight losses at $210^{\circ} \mathrm{C}$ ). Moreover the thermogravimetric profile is maintained (compared to that of films prepared without IL) although the new profiles present lower weight losses in the temperature range between 300 and $450{ }^{\circ} \mathrm{C}$. The higher thermal stability of the anion bis(trifluoromethylsulfonyl)imide and its advantages to maintain or to enhance the thermal stability of suspension-based PVC films have been previously reported in the literature ${ }^{30}$ and are further confirmed in the present work for an emulsion-based PVC.

The influence of plastisol aging on the thermal stability of the films is also presented in Table 2. As can be seen, aging delays $T_{\text {peak }}$ and decreases weight losses at $210^{\circ} \mathrm{C}$ which means that aging improves the thermal stability of films prepared with or without PhILs. These results are in agreement with rheological data previously discussed and show that aging enhances E-PVC particles solvency (and swelling) by the plasticizer (or plasticizer + PhIL mixture), with a consequent positive effect on the thermal stability of the films obtained from those plastisols. This effect is particularly evident for the plastisol formulated only with DINP, which showed a marked time- 
Table 2. Thermomechanical Analyses Results for Plastisols Formulated without Ionic Liquid and with 15\% (w/w) Substitution of the Plasticizer by Ionic Liquid: Peak Temperature $\left(T_{\text {peak }}\right)$ from DTG Curves (Obtained from the First Derivative of the Weight Loss vs Temperature Curve Measured by TGA); Weight Loss Percentage at $210{ }^{\circ} \mathrm{C}$ (Measured by TGA) and Glass Transition Temperature $\left(T_{\mathrm{g}}\right)$; Storage Modulus $\left(E^{\prime}\right)$ and Loss Modulus $\left(E^{\prime \prime}\right)$ at Different Temperatures Measured by DMTA ${ }^{a}$

\begin{tabular}{|c|c|c|c|c|c|c|c|c|c|c|c|c|c|c|}
\hline \multirow[b]{2}{*}{ plastisol } & \multirow{2}{*}{$\begin{array}{c}T_{\mathrm{p}} \\
\left({ }^{\circ} \mathrm{C}\right)\end{array}$} & \multirow{2}{*}{$\begin{array}{c}\text { wt loss } \\
\left(\text { at } 210{ }^{\circ} \mathrm{C}\right) \\
(\%)\end{array}$} & \multicolumn{2}{|c|}{$T_{\mathrm{g}}\left({ }^{\circ} \mathrm{C}\right)$} & \multicolumn{5}{|c|}{$E^{\prime}(\mathrm{MPa})$} & \multicolumn{5}{|c|}{$E^{\prime \prime}(\mathrm{MPa})$} \\
\hline & & & $\max E^{\prime \prime}$ & $\begin{array}{c}\max \\
\tan \delta\end{array}$ & $-50{ }^{\circ} \mathrm{C}$ & $-25^{\circ} \mathrm{C}$ & $0{ }^{\circ} \mathrm{C}$ & $25^{\circ} \mathrm{C}$ & $50{ }^{\circ} \mathrm{C}$ & $-50{ }^{\circ} \mathrm{C}$ & $-25{ }^{\circ} \mathrm{C}$ & $0{ }^{\circ} \mathrm{C}$ & $25{ }^{\circ} \mathrm{C}$ & $50^{\circ} \mathrm{C}$ \\
\hline \multirow[t]{2}{*}{ DINP } & 268.6 & 3.0 & -52.3 & -31.6 & 611.7 & 6.5 & 0.4 & 0.2 & 0.1 & 234.2 & 5.3 & 0.01 & 0.02 & 0.001 \\
\hline & 287.0 & 1.8 & -49.3 & -30.2 & 98.9 & 1.2 & 0.2 & 0.2 & 0.1 & 24.3 & 1.0 & 0.02 & 0.01 & 0.001 \\
\hline \multirow[t]{2}{*}{ DINP/Ph-DCA/15 } & 240.6 & 18.4 & -52.9 & -30.5 & 528.1 & 6.5 & 0.7 & 0.3 & 0.1 & 185.6 & 5.9 & 0.01 & 0.03 & 0.001 \\
\hline & 246.6 & 10.3 & -50.0 & -26.8 & 207.5 & 2.5 & 0.2 & 0.1 & 0.1 & 52.3 & 2.3 & 0.03 & 0.01 & 0.004 \\
\hline \multirow[t]{2}{*}{$\mathrm{DINP} / \mathrm{Ph}-\mathrm{Tf}_{2} \mathrm{~N} / 15$} & 282.7 & 2.8 & -51.8 & -30.6 & 78.2 & 2.1 & 0.3 & 0.2 & 0.2 & 22.8 & 1.4 & 0.06 & 0.01 & 0.006 \\
\hline & 287.0 & 1.6 & -50.3 & -26.9 & 102.2 & 2.4 & 0.2 & 0.1 & 0.1 & 25.5 & 1.7 & 0.04 & 0.01 & 0.001 \\
\hline \multirow[t]{2}{*}{ CITROFOL } & 293.0 & 1.2 & -58.3 & -35.0 & 33.5 & 1.6 & 0.2 & 0.1 & 0.1 & 1.3 & 0.8 & 0.03 & 0.01 & 0.006 \\
\hline & 300.6 & 0.9 & -54.7 & -32.8 & 69.4 & 3.3 & 0.4 & 0.4 & 0.3 & 23.8 & 1.7 & 0.1 & 0.05 & 0.02 \\
\hline \multirow[t]{2}{*}{ CITROFOL/Ph-DCA/15 } & 243.8 & 15.5 & -58.1 & -30.6 & 97.6 & 2.7 & 0.3 & 0.2 & 0.2 & 37.7 & 2.0 & 0.04 & 0.007 & 0.001 \\
\hline & 253.3 & 11.0 & -53.1 & -27.1 & 548.1 & 11.1 & 0.8 & 0.4 & 0.1 & 168.6 & 9.2 & 0.3 & 0.06 & 0.02 \\
\hline \multirow[t]{2}{*}{ CITROFOL/Ph-Tf ${ }_{2} \mathrm{~N} / 15$} & 291.0 & 1.3 & -59.5 & -35.6 & 17.3 & 0.9 & 0.2 & 0.1 & 0.01 & 6.3 & 0.4 & 0.04 & 0.1 & 0.003 \\
\hline & 302.6 & 0.9 & -57.3 & -31.1 & 120.4 & 8.3 & 0.7 & 0.3 & 0.1 & 38.4 & 3.0 & 0.2 & 0.05 & 0.01 \\
\hline
\end{tabular}

${ }^{a}$ For each sample the first and the second rows represent data measured for fresh plastisols and after 14 aging days.
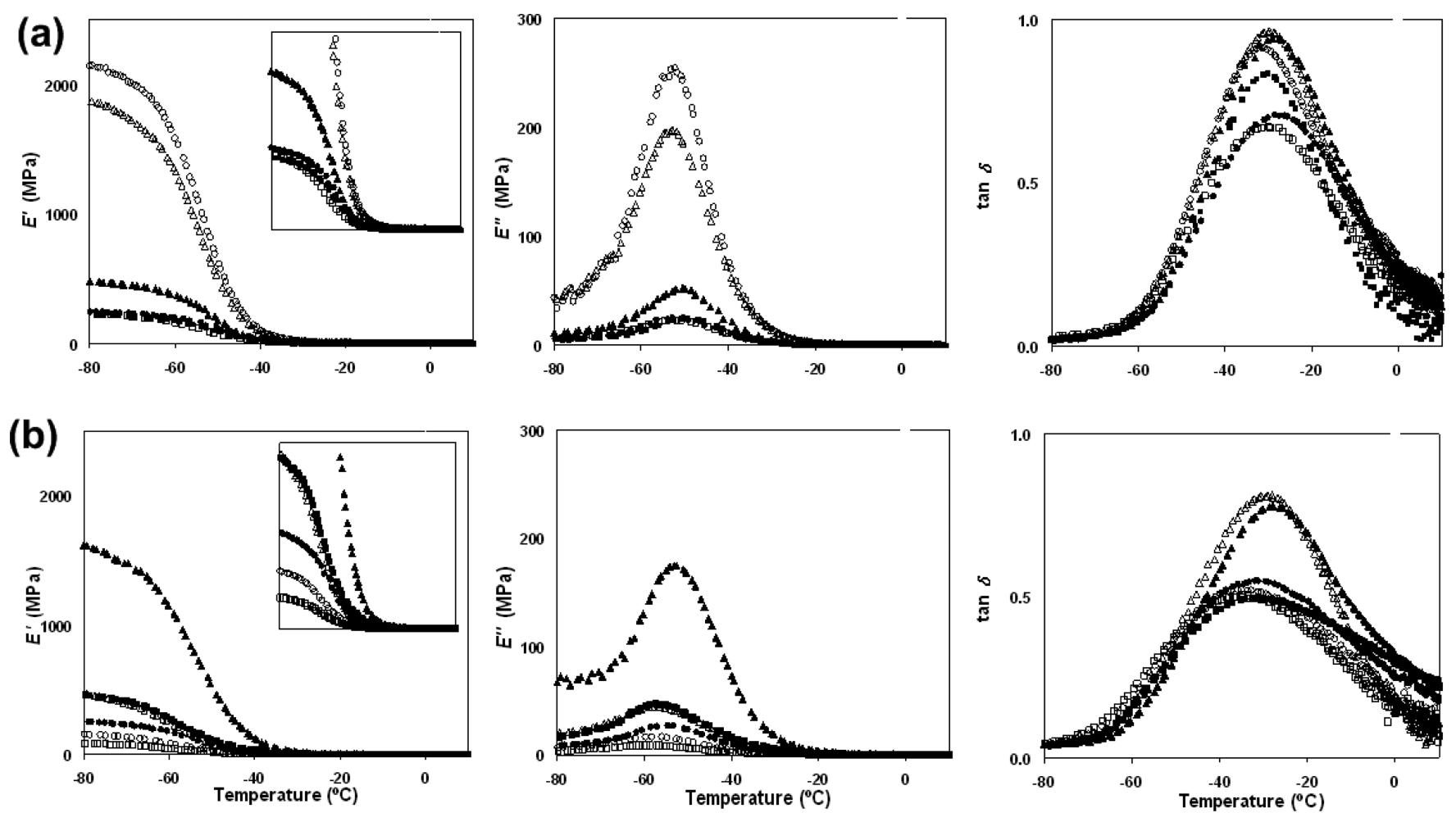

Figure 5. DMTA profiles of films obtained from fresh plastisols (open symbols) and 14 days aged plastisols (filled symbols) formulated with DINP (a) and CITROFOL (b) without ionic liquid $(\mathrm{O}, \boldsymbol{\bullet})$ and with $15 \%(\mathrm{w} / \mathrm{w})$ substitution of the plasticizer by Ph-DCA $(\Delta, \mathbf{\Delta})$ and by $\mathrm{Ph}-\mathrm{Tf}_{2} \mathrm{~N}(\square$, 口).

dependent rheological behavior and the most pronounced increase in the thermal stability of the resultant film after aging $\left(T_{\text {peak }}\right.$ increases by $\left.18{ }^{\circ} \mathrm{C}\right)$. Similar tendencies were observed for all of the other films although to a lower extent, most probably due to the higher stability of the corresponding plastisols.

When proposing the use of alternative plasticizers, it is important to guarantee that they are able to maintain, or rather to improve, the thermomechanical properties of the final materials. The plasticizing efficiencies of the employed plasticizers and plasticizer + PhIL mixtures were evaluated by DMTA, and the results are presented in Table 2. $T_{\mathrm{g}}$ of the films was taken at the maximum of the damping factor curve $(\tan \delta)$, as usually reported in the literature, but also at the maximum of the loss modulus $\left(E^{\prime \prime}\right)$, due to its practical interest for industrial applications, since at this temperature the change from the vitreous to the rubbery state is more accentuated. The profiles obtained in the temperature range between -80 and $25{ }^{\circ} \mathrm{C}$ and shown in Figure 5 for DINP-based (Figure 5a) and CITROFOL-based (Figure 5b) films. Results show that 
CITROFOL has higher plasticizing capacity (compared to DINP) since it originates films with lower $T_{\mathrm{g}}\left(T_{\mathrm{g}}\right.$ decreases by 6 and $3{ }^{\circ} \mathrm{C}$ in terms of maximum of $E^{\prime \prime}$ and $\tan \delta$, respectively) and significantly lower storage modulus, $E^{\prime}$ ( $\sim 95 \%$ lower than for DINP, at $-50{ }^{\circ} \mathrm{C}$ ). The behavior observed for CITROFOLbased films may be due to lower incorporation of this plasticizer into the E-PVC particles (lower increase in viscosity over time) which probably led to partial gelation without compromising the mechanical properties of the films.

The incorporation of both PhILs into the PVC-plasticizer systems significantly improved the plasticizing capacity of DINP, and this effect is particularly evident when using Ph$\mathrm{Tf}_{2} \mathrm{~N}$ for which a significant decrease (up to $87 \%$ at $-50^{\circ} \mathrm{C}$ ) in $E^{\prime}$ is observed, mainly at lower temperatures (below $0{ }^{\circ} \mathrm{C}$, as shown in Table 2). However, this effect is not noticed when comparing $T_{\mathrm{g}}$ values. This is because $T_{\mathrm{g}}$ is defined as the ratio between the dynamic loss modulus $E^{\prime \prime}$ (representing the viscous portion) and the dynamic storage modulus $E^{\prime}$ (representing the elastic portion), and both were found to decrease as shown in Table 2. The enhancement of the thermomechanical properties of the films at negative temperatures is a relevant and interesting result for upholstery manufacturers which are required to test their products according to restrict standards that include performance and resistance testing at negative temperatures (below $-10{ }^{\circ} \mathrm{C}$ ). Those performance tests are required to avoid cracking and damage of the material when used at extreme temperature conditions. Therefore, PhIL incorporation seems to be advantageous at those harsher conditions due to their broad liquid range (low melting and high boiling points) in which they perform better when other conventional solvents/additives start to fail.

The better plasticizing performance of $\mathrm{Ph}-\mathrm{Tf}_{2} \mathrm{~N}$ when compared to Ph-DCA can be explained based on the chemical nature of the anions and on the interaction that they may establish with the PVC chains (as discussed earlier). The differences in the molecular weights of the anions $(280.15 \mathrm{~g} /$ mol for bis(trifluoromethylsulfonate) imide compared to 67.05 $\mathrm{g} / \mathrm{mol}$ for dicyanamide) as well as their different polarizability, and hydrogen-bonding capacities, ${ }^{39}$ may justify the differences observed in their plasticization efficiency. More studies on the PVC-ionic liquids interactions are needed in order to deeply understand the observed results.

The effect of plastisol aging (after 14 storage days) on the thermomechanical properties of the films is also given in Table 2 and represented in Figure 5. Results show that aging has a huge impact on the storage modulus of DINP and DINP/PhDCA $/ 15$ samples, which decreases by $\sim 80 \%$ and $\sim 60 \%$, respectively (at $-50{ }^{\circ} \mathrm{C}$ ) while it increases for the $\mathrm{DINP} / \mathrm{Ph}$ $\mathrm{Tf}_{2} \mathrm{~N} / 15$ sample $(\sim 30 \%)$. This effect is not reflected in the $T_{\mathrm{g}}$ values of the DINP-based films (which actually increase after aging), because, as mentioned, $T_{\mathrm{g}}$ values also depend on changes in the loss modulus of the films. On the contrary, aging leads to an increase in $E^{\prime}$ of CITROFOL-based films according to the following sequence: CITROFOL < CITROFOL/Ph$\mathrm{Tf}_{2} \mathrm{~N} / 15 \ll \mathrm{CITROFOL} / \mathrm{Ph}-\mathrm{DCA} / 15 . T_{\mathrm{g}}$ values also increase for all of the samples (Table 2). In this case aging led to a decrease in the flexibility of the films probably due to partial volatility and diffusion of CITROFOL throughout the polymer matrix as well as a possible partial hydrolysis of CITROFOL over time. ${ }^{44}$ The results obtained for plastisols formulated only with DINP or CITROFOL are in agreement with rheological aging profiles previously discussed. In fact, DINP-based plastisols need more time to ensure efficient swelling of the E-PVC particles which is an essential condition to promote good gelation and obtain flexible materials with the envisaged thermomechanical properties. However, no clear tendency between the rheological profiles and the thermomechanical results was observed for plastisols formulated with PhILs. These results seem to indicate that, in these cases, PVC particles' solvation and swelling are not the only factors controlling the gelation process which may also depend on specific PVC-plasticizer-PhIL interactions.

\section{CONCLUSION}

The results obtained in this work demonstrated that it is possible to partially substitute conventional PVC plasticizers, such as DINP and CITROFOL, by phosphonium-based ILs (trihexyl(tetradecyl) phosphonium dicyanamide, Ph-DCA) and trihexyl(tetradecyl) phosphonium bis(trifluoromethylsulfonyl)imide, $\mathrm{Ph}-\mathrm{Tf}_{2} \mathrm{~N}$ ) and obtain thermally stable and flexible films. The incorporation of both PhILs significantly affected the rheological behavior of the plastisols and their particle size distributions with aging, this effect being more pronounced for formulations prepared with Ph-DCA. These results were discussed in terms of probable stronger Ph-DCA/PVC interactions as confirmed by the lower mixing enthalpies calculated for systems with Ph-DCA.

Plastisol aging had an important impact on the thermomechanical properties of PVC films plasticized only with DINP; however no significant improvements were observed for all of the other studied plastisols. This means that, from a practical point of view, the incorporation of PhILs may avoid plastisols storage that otherwise would be necessary to stabilize the plastisol and guarantee efficient plasticization (enhanced thermomechanical properties). When comparing both PhILs, it was shown that $\mathrm{Ph}-\mathrm{Tf}_{2} \mathrm{~N}$ enhanced the thermal stability of the films at processing temperatures $\left(\sim 210^{\circ} \mathrm{C}\right)$ and the flexibility of the films (decrease in the storage modulus) at negative temperatures. This is a relevant achievement in order to avoid cracking or damage of the plasticized materials when they are envisaged to perform at harsher environmental conditions.

Therefore, this work permitted the conclusion that phosphonium trihexyl(tetradecyl) bis(trifluoromethylsulfonyl)imide represents a viable nonphthalate plasticizer alternative to partially substitute DINP or CITROFOL in E-PVC plasticization with improved thermal stability and thermomechanical properties.

\section{ASSOCIATED CONTENT}

\section{S Supporting Information}

Composition of the prepared plastisol samples (Table S1), the E-PVC (E1970P) powder properties (Table S2), the particle size distributions of plastisols during aging (Table S3), the PSD distributions of E-PVC powder and plastisols formulated with DINP and CITROFOL (Figure S1), and the visual aspect of the E-PVC-based films plasticized obtained from fresh plastisols formulated with and without ionic liquids after immersion in acetone for $45 \mathrm{~min}$ (Figure S2). This material is available free of charge via the Internet at http://pubs.acs.org.

\section{AUTHOR INFORMATION}

\section{Corresponding Authors}

*(H.C.d.S.) E-mail: hsousa@eq uc.pt. Phone: +351-239798749. Fax: +351-239-798703. 
*(M.G.R.) E-mail: mgr@eq uc.pt. Phone: +351-239-798725. Fax: +351-239-798703.

\section{Notes}

The authors declare no competing financial interest.

\section{ACKNOWLEDGMENTS}

This work was financially supported by Fundação para a Ciência e Tecnologia (FCT-MEC) under Contracts PTDC/ QUI/71398/2006 and PEst-C/EQB/UI0102/2011. A.M.A.D. acknowledges FCT-MEC for the fellowship SFRH/BPD/ 40409/2007. We acknowledge the TMG Automotive support for this work and Cátia Costa for her help with the DMTA measurements.

\section{REFERENCES}

(1) Marcilla, A.; Garcia, J. C. Theoretical model for the gelation and fusion mechanisms of PVC plastisols based on rheological measurements. Eur. Polym. J. 1997, 34 (3), 1341-1348.

(2) Howick, C. Studies of molecular interactions between PVC and plasticisers. Plast., Rubber Compos. Process. Appl. 1995, 23 (1), 53-60.

(3) Garcia, J. C.; Marcilla, A. Rheological study of the influence of the plasticizer concentration in the gelation and fusion processes of PVC plastisols. Polymer 1998, 39 (15), 507-3514.

(4) Howick, C. New developments in emulsion-PVC polymerisation to produce polymers with the potential of reduced or zero VOC requirements when used in plastisols applications. Green Chem. 2007, 9 (3), 243-246.

(5) Nakajima, N.; Harrell, E. R. Rheology of PVC Plastisol: Particle Size Distribution and Viscoelastic Properties. J. Colloid Interface Sci. 2001, 238 (1), 105-115.

(6) Rasteiro, M. G.; Antunes, E. Correlating the Rheology of PVCBased Pastes with Particle Characteristics. Part. Sci. Technol. 2005, 23 (4), 361-375.

(7) Daniels, P. H. A Brief Overview of Theories of PVC Plasticization and Methods Used to Evaluate PVC-Plasticizer Interaction. J. Vinyl Addit. Technol. 2009, 15 (4), 219-223.

(8) Garcia-Quesada, J. C.; Marcilla, A.; Beltrán, M. Study of the Processability of Commercial PVC Plastisols by Rheology. J. Vinyl Addit. Technol. 1999, 5 (1), 31-36.

(9) Rasteiro, M. G.; Tomás, A.; Ferreira, L.; Figueiredo, S. PVC Paste Rheology: Study of Process Dependencies. J. Appl. Polym. Sci. 2009, 112 (5), 2809-2821.

(10) Boudhani, H.; Lainé, C.; Fulchiron, R.; Bounor-Legaré, V.; Cassagnau, P. Viscoelasticity and Mechanical Properties of Reactive PVC Plastisols. Polym. Eng. Sci. 2009, 49 (6), 1089-1098.

(11) Tomás, A.; Rasteiro, M. G.; Gando-Ferreira, L.; Figueiredo, S. Rheology of Poly(vinyl chloride) Plastisol: Effect of a particular nonionic cosurfactant. J. Appl. Polym. Sci. 2009, 115 (1), 599-607.

(12) Marcilla, A.; Garcia, J. C.; Beltran, M. Study of the flow properties and the ageing process in PVC plastisols from comercial PVC resins. Eur. Polym. J. 1997, 33 (5), 753-759.

(13) Nakajima, N.; Harrell, E. R. Viscosity Aging of Poly(vinyl chloride) Plastisol: Effect of the Resin Type and Plasticizer Type. J. Appl. Polym. Sci. 2005, 95 (2), 448-464.

(14) Barroso, E. G.; Duarte, F. M.; Couto, M.; Maia, J. M. A Rheological Study of Emulsion and Microsuspension-Based PVC Plastisols. J. Appl. Polym. Sci. 2008, 109 (1), 664-673.

(15) Nakajima, N.; Kwak, S.-Y. Effect of plasticizer type on gelation and fusion of PVC plastisol, dialkyl phthalate series. J. Vinyl Technol. 1991, 13 (4), 212-222.

(16) Zoller, A.; Marcilla, A. Soft PVC foams: Study of the gelation, fusion, and foaming processes. I. Phthalate ester plasticizers. J. Appl. Polym. Sci. 2011, 121 (3), 1495-1505.

(17) Demir, A. P. T.; Ulutan, S. Migration of Phthalate and NonPhthalate Plasticizers Out of Plasticized PVC Films into Air. J. Appl. Polym. Sci. 2013, 128 (3), 1948-1961.
(18) Chiellini, F.; Ferri, M.; Morelli, A.; Dipaola, L.; Latini, G. Perspectives on alternatives to phthalate plasticized poly(vinyl chloride) in medical devices applications. Prog. Polym. Sci. 2013, 38 (7), 1067-1088.

(19) Heudorf, U.; Mersch-Sundermann, V.; Angerer, J. Phthalates: Toxicology and exposure. Int. J. Environ. Health 2007, 210 (5), 623634.

(20) Yu, B. Y.; Lee, A. R.; Kwak, S. Y. Gelation/fusion behavior of PVC plastisol with acyclodextrin derivative and an anti-migration plasticizer in flexible PVC. Eur. Polym. J. 2012, 48 (5), 885-895.

(21) Erythropel, H. C.; Maric, M.; Cooper, D. G. Designing green plasticizers: Influence of molecular geometry on biodegradation and plasticization properties. Chemosphere 2012, 86 (8), 759-766.

(22) Gil, N.; Negulescu, I.; Saska, M. Evaluation of the effects of biobased plasticizers on thermal and mechanical properties of poly(vinyl chloride). J. Appl. Polym. Sci. 2006, 102 (2), 1366-1373.

(23) Fenollar, O.; García, D.; Sánchez, L.; López, J.; Balar, R. Optimization of the curing conditions of PVC plastisols based on the use of an epoxidized fatty acid ester plasticizer. Eur. Polym. J. 2009, 45 (9), 2674-2684.

(24) Benaniba, M. T.; Massardier-Nageotte, V. Evaluation effects of Biobased Plasticizer on the thermal, mechanical, dynamic mechanical properties, and permanence of plasticized PVC. J. Appl. Polym. Sci. 2010, 118 (6), 3499-3508.

(25) Marcilla, A.; Garcia, S.; Garcia-Quesada, J. C. Migrability of PVC plasticizers. Polym. Test. 2008, 27 (2), 221-233.

(26) Rahman, M.; Brazel, C. S. Ionic liquids: New generation stable plasticizers for poly(vinyl chloride). Polym. Degrad. Stab. 2006, 91 (12), 3371-3382.

(27) Lin, X. H.; Wang, S. Study on ionic liquid (bmin) $\mathrm{PH}_{6}$ and (hmin) $\mathrm{PF}_{6}$ as plasticizer for PVC paste resin. Polym. Bull. 2011, 67 (7), $1273-1283$.

(28) Choi, S. Y.; Rodríguez, H.; Mirjafari, A.; Gilpin, D. F.; McGrath, S.; Malcolm, K. R.; Tunney, M. M.; Rogers, R. D.; McNally, T. Dual functional ionic liquids as plasticisers and antimicrobial agents for medical polymers. Green Chem. 2011, 13, 1527-1535.

(29) Wang, S.; Hou, L. Application of four ionic liquids as plasticizers for PVC Paste Resin. Iran. Polym. J. 2011, 20 (12), 989-997.

(30) Dias, A. M. A.; Marceneiro, S.; Braga, M. E. M.; Coelho, J. F. J.; Ferreira, A. G. M.; Simões, P. N.; Veiga, H. I. M.; Tomé, L. C.; Marrucho, I. M.; Esperança, J. M. S. S.; Matias, A. A.; Duarte, C. M. M.; Rebelo, L. P. N.; de Sousa, H. C. Phosphonium-based ionic liquids as modifiers for biomedical grade poly(vinylchloride). Acta Biomater. 2012, 8 (3), 1366-1379.

(31) Rahman, M.; Brazel, C. S. The plasticizer market: An assessment of traditional plasticizers and research trends to meet new challenges. Prog. Polym. Sci. 2004, 29 (12), 1223-1248.

(32) Bradaric, C. J.; Downard, A.; Kennedy, C.; Robertson, A. J.; Zhou, Y. Industrial preparation of phosphonium ionic liquids. Green Chem. 2003, 5, 143-152.

(33) Fraser, K.; MacFarlane, D. R. Phosphonium-based ionic liquids: An overview. Aust. J. Chem. 2009, 62, 309-321.

(34) Ferguson, L.; Scovazzo, P. Solubility, diffusivity and permeability of gases in phosphonium-based room temperature ionic liquids: Data and correlations. Ind. Eng. Chem. Res. 2007, 46 (4), 1369-1374.

(35) Ferreira, A. G. M.; Simões, P. N.; Ferreira, A. F.; Fonseca, M. A.; Oliveira, M. S. A.; Trino, A. S. M. Transport and thermal properties of quaternary phosphonium ionic liquids and IoNanofluids. J. Chem. Thermodyn. 2013, 64, 80-92.

(36) Shah, V. Handbook of Plastics Testing and Failure Analysis; John Wiley \& Sons: Hoboken, NJ, USA, 2007.

(37) van Krevelen, D. W.; Nijenhuis, K. Properties of polymers: Their correlation with chemical structure; their numerical estimation and prediction form additive group contributions; Elsevier: Amsterdam, 2009.

(38) Kilaru, P. K.; Scovazzo, P. Correlations of Low Pressure Carbon Dioxide and Hydrocarbon Solubilities in Imidazolium-, Phosphoniumand Ammonium-Based Room-Temperature Ionic Liquids. Part 2. Using Activation Energy of Viscosity. Ind. Eng. Chem. Res. 2008, 47 (3), 910-919. 
(39) Batista, M.; Neves, C.; Carvalho, P.; Gani, R.; Coutinho, J. Chameleonic behavior of ionic liquids and its impact on the estimation of solubility parameters. J. Phys. Chem. B 2011, 115, 12879-12888.

(40) Crowhurst, L.; Mawdsley, P. R.; Perez-Arlandis, J. M.; Salter, P. A.; Welton, T. Solvent-solute interactions in ionic liquids. Phys. Chem. Chem. Phys. 2003, 5, 2790-2794.

(41) Wypych, G. Handbook of Plasticizers; Elsevier: Toronto, 2004.

(42) Simões, P. N.; Coelho, J. F. J.; Gonçalves, P. M. F. O.; Gil, M. H. Comparative non-isothermal kinetic analysis of thermal degradation of poly(vinyl chloride) prepared by living and conventional free radical polymerization methods. Eur. Polym. J. 2009, 45 (7), 1949-1959.

(43) Zhao, T.; Zhou, Q.; He, X. L.; Wei, S. D.; Wang, L.; van Kasteren, J. M. N.; Wang, Y. Z. A highly efficient approach for dehydrochlorinating polyvinyl chloride: Catalysis by 1-butyl-3methylimidazolium chloride. Green Chem. 2010, 12, 1062-1065.

(44) Persico, P.; Ambrogi, V.; Acierno, D.; Carfagna, C. Processability and mechanical properties of commercial PVC plastisols containing low-environmental-impact plasticizers. J. Vinyl Addit. Technol. 2009, 15 (3), 139-146. 